\title{
UTILIZAÇÃO DE ADUBAÇÃO ORGÂNICA EM PASTAGEM DE CAPIM-BUFFEL (CENCHRUS CILIARIS CV. MOLOPO)*
}

\author{
USE OF ORGANIC FERTILIZER IN BUFEEL GRASS \\ (CENCHRUS CILIARIS CV. MOLOPO) PASTURE
}

\author{
Edvan, R.L. ${ }^{1}$, Santos, E.M. ${ }^{2}$, Vasconcelos, W.A. ${ }^{1}$, Souto Filho, L.T. ${ }^{1}$, Borburema, J.B. ${ }^{1}$, \\ Medeiros, G.R. ${ }^{1}$ e Andrade, A.P. ${ }^{2}$
}

${ }^{1}$ Instituto Nacional do Semi-árido. Av. Floriano Peixoto, 618. Centro. Campina Grande-PB. CEP 58100-001. Brasil.agroloiola@hotmail.com

${ }^{2}$ Centro de Ciências Agrárias. Universidade Federal da Paraíba. Campus II. Areia-PB. CEP 58397-000. Brasil. edson@cca.ufpb.br

\section{PalABRAs ClaVe ADICIONALES}

Crescimento. Manejo. Nutrientes minerais.

\section{RESUMO}

Objetivou-se analisar e comparar com outras fontes de adubo o efeito da digesta de bovinos sobre características estruturais, morfogênicas e de produção do capim buffel. O estudo foi conduzido na Estação Experimental do Instituto Nacional do Semi-Árido, localizado em Campina Grande, PB, Brasil. Utilizou-se um pasto de capim-buffel cultivar Molopo, já estabelecido. A área experimental foi dividida em 24 parcelas com $4 \mathrm{~m}^{2}$ cada, sendo utilizado um delineamento de blocos completos ao acaso, arranjado em esquema de parcelas subdivididas no tempo. Os tratamentos consistiram da utilização de digesta ou esterco bovino (5 e 10 toneladas de matéria seca/ha para ambos) e adubação química $200 \mathrm{~kg} / \mathrm{h}$ a da fórmula 40:10:40. Não houve interação entre a adubação e época de corte $(p>0,10)$. Para a adubação houve efeito $(p<0,10)$ na produção de matéria verde, tendo o tratamento com adubo químico obtido maior produção. Para a produção de matéria seca, observou-se diferença $(p<0,10)$, com o esterco bovino e a digesta nas maiores dosagens resultando em maiores produções. O maior $(p<0,10)$ número de perfilhos basais foi observado para o tratamento com digesta na maior dose. Não houve efeito $(p>0,10)$ da adubação para a relação lâmina foliar/colmo, taxa de aparecimento de folhas e

* Parte da monografia do primeiro autor para obtenção do título de Pós-Graduado latu senso.

\section{AdDitional KEYWORDS}

Growth. Management. Mineral nutrients.

número de folhas vivas por perfilhos basais, porém observou-se efeito $(p<0,10)$ para o filocrono, principalmente no tratamento com maior dosagem do esterco bovino. Em relação ao efeito da época de corte, observou-se diferença $(p<0,10)$ para produção de matéria verde e seca, relação lâmina foliar/colmo, número de perfilhos basais, taxa de aparecimento de folhas, número de folhas por perfilhos basais, filocrono e altura de corte. A utilização de digesta promove incrementos no desenvolvimento e produção do capim buffel, sendo uma alternativa ecologicamente correta para ser utilizada como adubo orgânico.

\section{SUMMARY}

The objective of this experiment was to compare with other fertilizer sources the effect of bovine digestive content on structural, morphogenetic and production characteristics of buffel grass. The study was carried out at Estação Experimental do Instituto Nacional do Semi-árido, located in Campina Grande, PB, Brazil. A previously implanted pasture of buffel grass, cultivar Molopo was used. Experimental area was split in $24\left(4 \mathrm{~m}^{2}\right)$ experimental unities and a completely randomized block in a split plot scheme, split at time. Treatments were 5 and 10 ton of dry matter per ha of digestive content or bovine manure. For mineral fertilizer treatment 40:10:40 formule was used applying 
$200 \mathrm{~kg}$ of mix per ha. There was not interaction between fertilization and time cut $(p>0.10)$. Fertilization influenced $(p<0.10)$ fresh matter production; mineral fertilizer treatment presented higher production. For dry matter production difference was verified $(p<0.10)$; cattle manure and digestive content in higher dose resulted in greater productions. Higher $(p<0.10)$ number of tillers was verified for digestive content in higher dose. There was not effect $(p>0.10)$ of fertilization for leaf/steam ratio, leaf appearence rate and number of green leafes per tiller, whereas effect $(p<0.10)$ for phyllocron was obseved, mainly for higher cattle manure dose. With relation to time of cutting there was difference $(p<0.10)$ for fresh and dry matter production, leaf/steam ratio, leaves appearence rate, number of green leaves per tiller, phyllocron and height of cut. The digestive content promote increase in buffel grass production, presenting a viable alternative to be used as organic fertilizer.

\section{INTRODUÇÃO}

Nos últimos anos a humanidade está sofrendo cada vez mais com as conseqüências ambientais, devido às constantes práticas de degradação do meio ambiente, a deposição de dejetos em mananciais de água vem contribuindo para o aumento dos índices de poluição. A busca por alternativas de utilização desses dejetos é prioritária, já que permitiria a reciclagem de nutriente, promovendo a utilização de um produto que seria descartado.

Os resíduos sólidos encontrados dentro do trato gastrointestinal dos animais abatidos são chamados de digesta. A digesta é um resíduo de abatedouro que é descartado no meio ambiente sem nenhum tratamento, causando poluição e trazendo prejuízos ecológicos. Um grande problema encontrado por abatedouro de bovinos é a grande quantidade de resíduo sólido gerado. Segundo Espinoza et al. (1998), este tipo de indústria gera uma quantidade de efluente por animal processado de 1,1 a 2,9 $\mathrm{m}^{3}$. Multiplicando esse valor pela quantidade de animais abatidos por dia nos abatedouros do Brasil se tem uma grande quantidade de material orgânico que poderia ser utilizada como adubo em áreas de pastagens.

A responsabilidade das agroindústrias com os resíduos gerados durante o processamento, atualmente não é só vinculada à legislação vigente, mas também melhora a visibilidade do produto a ser comercializado principalmente no mercado externo. Durante o processo de abate são gerados resíduos sólidos, como o conteúdo ruminal dos bovinos, e resíduos líquidos, como as águas de lavagem de carcaça e de equipamentos e resíduos de sangue, que devem receber tratamentos específicos para que possam ser dispostos sem riscos de contaminação ou degradação do ambiente (Mourales et al., 1998).

Segundo Braile (1971), o melhor meio de tratar efluentes de frigoríficos seria juntálos com o esgoto doméstico, devido a sua semelhança, mas em áreas que esta prática não é possível, as indústrias deverão ter suas próprias estações de tratamento. Outra solução para que a disposição final da digesta não acabe em corpos de água, seria dar um destino mais adequado a mesma, como é o caso da agricultura, que necessita constantemente, de nutrientes para produção de alimentos. Com a utilização da digesta, será possível diminuir a carga de poluentes que são liberados todos os dias em mananciais de água, contribuindo assim, com o meio ambiente e com a produção agropecuária.

Entretanto, apesar da ampla aceitação do esterco como adubo orgânico, seu uso pode apresentar algumas limitações. Em primeiro lugar, sua disponibilidade, nas propriedades rurais típicas do semi-árido nordestino é, geralmente, insuficiente para suprir as necessidades nutricionais das plantas nas áreas com culturas agrícolas (Menezes e Sampaio, 2002).

Menezes e Sampaio (2002), em um estudo com um modelo de simulação, estimaram que o $\mathrm{P}$ contido no esterco acumulado no curral em uma propriedade típica do Curimataú paraibano, só seria suficiente 
para repor apenas $12 \%$ do P retirado do solo pelas culturas agrícolas de subsistência. Sendo que nas áreas de maior tradição agrícola, que apresentam maiores níveis de precipitação pluviométrica, é comum que os agricultores comprem esterco de regiões circunvizinhas, elevando assim os custos de produção (Sabourin et al., 2000).

Dessa forma, é importante estudar outras fontes de matéria orgânica para as plantas forrageira no Semi-Árido, para se ter assim, uma relação custo/benefício favorável ao produtor. Nagel et al. (2008), realizaram um estudo no estado do Mato Grosso do Sul, onde o adubo orgânico produzido a partir de digesta teve uma relação $\mathrm{C} / \mathrm{N}$ de $18-20$, $2 \%$ de $\mathrm{N}$ por $\mathrm{kg}, 3 \%$ de $\mathrm{P}$ por $\mathrm{kg}$ e $1 \%$ de $\mathrm{K}$ por $\mathrm{kg}$, e demonstraram que esse material pode ser um produto economicamente viável, por fornecer quantidade elevada de nutrientes a um custo reduzido.

Dentre algumas espécies avaliadas inicialmente com potencial forrageiro para o semi-árido brasileiro, o capim-buffel, foi o que apresentou o maior potencial forrageiro para a região (Oliveira et al., 1998). O capim Cenchrus ciliaris L. é altamente nutritivo, sendo considerado excelente para pastagem em áreas quente e seco, valorizado pela sua produção de forragem palatável e intermitente pastoreio durante períodos secos nos trópicos (Quraishi et al., 1993).

É importante realizar estudos que mostrem alternativas para a utilização de dejetos que poluam o meio ambiente. Devido à escassez de informações a respeito de práticas de manejo no capim-buffel baseados em conceitos de adubação orgânica, trabalhos dessa natureza são extremamente necessários.

Objetivou-se então, avaliar os efeitos da digesta sobre as características morfogênicas, características estruturais e a produtividade do capim-buffel.

\section{MATERIAL E MÉTODOS}

O experimento foi realizado na Estação
Experimental do Instituto Nacional do SemiÁrido-INSA, localizada no município de Campina Grande, PB. Foi utilizada uma pastagem de capim-buffel(Cenchrus ciliaris cv. Molopo) já implantada desde junho de 2006. Foram coletadas amostras do solo para análises químicas e de MO, obtendo-se os seguintes resultados: $\mathrm{pH}=6,3 ; \mathrm{P}=14 \mathrm{mg} /$ $\mathrm{kg} ; \mathrm{K}=80 \mathrm{mg} / \mathrm{kg} ; \mathrm{H}=1,63 \mathrm{cmolc} / \mathrm{kg} ; \mathrm{Al}=0,05$ $\mathrm{cmolc} / \mathrm{kg} ; \mathrm{Ca}=1,37 \mathrm{cmolc} / \mathrm{kg} ; \mathrm{Mg}=0,77$ $\mathrm{cmolc} / \mathrm{kg} ; \mathrm{MO}=19 \mathrm{~g} / \mathrm{kg}$. Com base neste resultado não foi necessário fazer a correção da acidez.

A área total utilizada no experimento foi dividida em 24 parcelas de $4 \mathrm{~m}^{2}$ cada, com linhas de bordaduras de $1 \mathrm{~m}$. Utilizou-se um delineamento experimental de blocos completos ao acaso, com quatro repetições, arranjado em um esquema de parcelas subdivididas no tempo, sendo os tratamentos representando as parcelas, que receberam as seguintes denominações: DR1; digesta dose 1; DR2: digesta dose 2; EB1: esterco bovino dose 1; EB2: esterco bovino dose 2; AQ: adubo químico e SA: sem adubo, e a época de colheita representando as subparcelas. Utilizaram-se duas doses de adubo orgânico (5 e 10 toneladas de matéria seca por hectare, representados respectivamente pelos números 1 e 2 nos tratamentos DR e EB). Como a digesta e o esterco bovino apresentaram teores diferentes de matéria seca, a quantidade total a ser aplicada foi ajustada de modo a atingir as doses preconizadas com base na matéria seca. Para a dose 1 da digesta, utilizou-se 6,5 toneladas da mesma por hectare, enquanto que para dose 2 foi utilizado 13 toneladas por hectare. $\mathrm{Na}$ dose 1 de esterco bovino se utilizou 5,5 toneladas por hectare, e na dose 2 utilizouse 11 toneladas por hectare. Para a adubação mineral, foi utilizado adubo com a seguinte formulação N-P-K: 40:10:40, sendo utilizado $200 \mathrm{~kg}$ da mistura por hectare.

A digesta foi obtida de um abatedouro do município de Campina Grande-PB e transportada para a Estação Experimental do INSA, onde foi colocada para secar ao sol, 
antes de ser utilizada. O esterco bovino foi obtido na própria Estação Experimental do INSA e foi curtido antes de ser utilizado. Amostras da digesta e do esterco bovino foram encaminhadas ao Laboratório de Análise de Solos, da Universidade Federal da Campina Grande, para determinação do teor de fósforo, e ao Laboratório de Nutrição Animal, do Departamento de Zootecnia da Universidade Federal da Paraíba, para análise de nitrogênio total, matéria seca e matéria orgânica. O esterco bovino apresen-tou os seguintes valores: $\mathrm{N}-0,78 \%$; $\mathrm{P}$ $0,87 \%$; K- $0,33 \%$ e MO- $15,94 \%$, enquanto que a digesta apresentou os seguintes valores N-2,0\%; P-2,0\%; K-1,0 e MO-38\%.

O experimento teve duração de 123 dias, compreendendo o período da estação chuvosa, que foi de março a julho de 2008 . Os intervalos entre cortes foram de 45 dias, e cada corte foi realizado a $20 \mathrm{~cm}$ do solo, em um total de três cortes. Antes do início do experimento, no início do período chuvoso (mês de março), foi realizado um corte de uniformização, também a $20 \mathrm{~cm}$ do solo, e efetuadas as adubações referentes aos tratamentos.

A altura média das parcelas experimentais foi medida utilizando-se uma régua de aço de $2 \mathrm{~m}$ de comprimento graduada em centímetros. Foram tomadas leituras em quatro pontos aleatórios por unidade experimental. A altura de cada ponto correspondeu à altura média do plano de folhas em torno da régua. Para monitorar a altura de resíduo, utilizou-se um quadrado de madeira confeccionado na altura de $20 \mathrm{~cm}$, que serviu de base para o corte com tesoura de jardinagem.

Para a determinação da biomassa de forragem produzida e de sua composição morfológica foram colhidas amostras representativas acima da altura de corte estabelecida. A forragem colhida foi pesada, e uma amostra representativa, de aproximadamente $200 \mathrm{~g}$, foi pré-seca em estufa de ventilação forçada a $65^{\circ} \mathrm{C}$, até atingir peso constante, para posterior determinação dos teores de matéria seca (MS).
Amostras de forragem de aproximadamente $500 \mathrm{~g}$ foram separadas manualmente nas frações das lâminas foliares e colmo (colmo + bainhas foliares), as quais foram pesadas e secas em estufa de circulação forçada de ar a $65^{\circ} \mathrm{C}$, até atingir peso constante. A determinação dos componentes morfológicos foi realizada durante todo o período experimental. Os valores de massa de forragem foram convertidos para $\mathrm{kg} / \mathrm{ha}$ de MS e os componentes morfológicos expressos como percentagem (\%) da massa de forragem.

Para a avaliação do número de perfilhos (basais e aéreos) foram utilizadas duas touceiras por unidade experimental. Estas foram selecionadas em pontos onde a altura representasse a condição média das parcelas, no momento da marcação das plantas. No início do período experimental, todos os perfilhos pertencentes às touceiras foram contados e marcados com arames revestidos de plástico de uma cor determinada. A cada nova amostragem, realizada sempre na condição de pós-corte, novos perfilhos foram marcados com cores diferentes e quantificados. Nessas mesmas touceiras foi avaliado com uma fita métrica o perímetro das touceiras ao final de cada avaliação, para se obter o diâmetro de touceira.

Ao longo do experimento, as plantas foram avaliadas quanto às características morfogênicas taxa de aparecimento foliar $(\mathrm{TApF})$ e filocrono, e à característica estrutural, número total de folhas vivas/ perfilhos. Para a contagem do número total de folhas vivas/perfilhos, foram marcados dois perfilhos basais por tratamento com fios de telefone coloridos, com os perfilhos basais sendo avaliados a cada sete dias, durante todo experimento. A cada corte foram escolhidos outros dois perfilhos basais. A taxa de aparecimento de folhas foi calculada dividindo-se o número total de folhas vivas no perfilho, respectivamente, pelo período de rebrotação. O cálculo era efetuado para cada perfilho marcado, de modo que o valor final constituía a média 
dos dois perfilhos basais por parcela, que correspondia um tratamento. O número de folhas vivas foi obtido sempre pelo máximo número de folhas durante o período de avaliação, que correspondia cada corte, após o período estabelecido de 45 dias. O filocrono foi estimado como o inverso da taxa de aparecimento de folhas (Skinner e Nelson, 1995).

Os dados arranjados por épocas de colheita foram submetidos à análise de variância e, as médias foram comparadas pelo teste de Tukey, adotando-se um nível de significância de $10 \%$. Os dados foram analisados utilizando-se o procedimento GLM do pacote estatístico SAS (SAS Institute, 1993).

\section{RESULTADOSEDISCUSSÃO}

Não houve interação entre a adubação e época de corte $(\mathrm{p}>0,10)$, de maneira que os dados serão apresentados e discutidos pelas médias dos tratamentos independentemente da época de corte e pelas médias de cada época, independentemente do tipo de adubo.

Houve efeito $(p<0,10)$ dos diferentes adubos utilizados para a produção de matéria verde (tabela I), sendo que o tratamento com adubo químico apresentou maior $(\mathrm{p}<0,10)$ produção. Provavelmente, isso se deve ao fato do adubo químico ter uma maior disponibilidade em relação aos outros e uma maior capacidade de acúmulo instantâneo de tecidos na planta, observação feita também por Santos Junior et al. (2004), que demonstraram o efeito positivo da adubação nitrogenada sobre a produção de forragem da Brachiaria brizantha cv. Marandu e o aumento na taxa de crescimento relativo e taxa assimilatória líquida.

Com relação à produção de matéria seca também houve diferença $(\mathrm{p}<0,10)$ para os diferentes tipos e dosagem de adubos, observando que, a adubação com digesta ou o esterco bovino nas maiores dosagens resultaram em maiores $(\mathrm{p}<0,10)$ produções, quando comparados ao tratamento sem
Tabela I. Valores médios e respectivos coeficientes de variação (CV\%) da produção de matéria verde (PMV), produção de matéria seca (PMS) e relação lâmina foliar/colmo $(L / C)$ em capim-buffel cv. Molopo, sobre diferentes formas de adubação, para os três cortes avaliados. (Average values and coefficient of variation of fresh matter production (PMV), dry matter production (PMS) and leaf/ steam ratio (L/C) in buffel grass $\mathrm{Cv}$. Molopo as a function of different fertilization ways).

\begin{tabular}{lcrr}
\hline Tratamentos & PMV (t/ha) & PMS (t/ha) & L/C \\
\hline Sem adubo & $6,2^{\mathrm{c}}$ & $1,3^{\mathrm{b}}$ & 1,05 \\
Adubo químico & $7,8^{\mathrm{a}}$ & $1,7^{\mathrm{ab}}$ & 1,03 \\
Digesta ruminal 1 & $6,4^{\mathrm{c}}$ & $1,5^{\mathrm{ab}}$ & 1,05 \\
Digeata ruminal 2 & $7,7^{\mathrm{ab}}$ & $1,8^{\mathrm{a}}$ & 1,01 \\
Esterco bovino 1 & $7,6^{\mathrm{ab}}$ & $1,7^{\mathrm{ab}}$ & 1,07 \\
Esterco bovino 2 & $7,7^{\mathrm{ab}}$ & $1,8^{\mathrm{a}}$ & 1,11 \\
& & & \\
CV (\%) & 17,3 & 20,94 & 25,63
\end{tabular}

Médias seguidas de letras diferentes nas colunas diferem entre si pelo teste de Tukey, ao nível de $10 \%$ de significância.

adubação. No caso da digesta, isso provavelmente ocorreu devido ao alto número de perfilhos (tabela II) observado nesse tratamento, assim, a ontogenia, que é a formação de perfilhos (Gomide, 1997), pode ter contribuído para o aumento da produção de matéria seca. Em relação ao esterco, a elevada produção de matéria seca se deve principalmente aos minerais nele encontrado, como mostrou o estudo feito por Durigon et al. (2002), onde praticamente todo o N, K e o P, adicionado via esterco, estava em sua forma disponível às plantas, contribuindo assim de forma significativa para a produção de matéria seca das plantas. As maiores produções de matéria seca nos tratamentos com adubos orgânicos podem ter sido devido ao maior tempo de contato com os nutrientes encontrados no adubo, ou mesmo à quantidade de nutrientes disponíveis, tendo em vista que ambos os adubos eram compostos por quantidades 
Tabela II. Valores médios e respectivos coeficientes de variação (CV \%) do número de perfilhos (NP), taxa de aparecimento de folhas (TApF), número de folhas vivas por perfilho (NFVP), filocrono (FILO), altura das plantas (AP), diâmetro da touceira (DIAM), taxa de aparecimento de perfilho em capim-buffel cv. Molopo, sobre diferentes formas de adubação. (Average values and variation coefficient of number of tillers (NP), leaf appearence rate (TApF), number of green leaves per tiller (NFVP) phyllocron (FILO), plant height (AP) and diameter of shoots (DIAM) in buffel grass $\mathrm{CV}$. Molopo as a function of different fertilization ways).

\begin{tabular}{lcccccc}
\hline Tratamentos & NP & $\begin{array}{c}\text { TApF } \\
\text { Folhas/dia }\end{array}$ & NFVP & $\begin{array}{c}\text { FILO } \\
\text { dias }\end{array}$ & $\begin{array}{c}\text { AC } \\
(\mathrm{cm})\end{array}$ & $\begin{array}{l}\text { DIAM } \\
(\mathrm{cm})\end{array}$ \\
\hline Sem adubo & $99^{\mathrm{b}}$ & 0,24 & 7,18 & $4,52^{\mathrm{ab}}$ & $82,7^{\mathrm{c}}$ & $39,2^{\mathrm{c}}$ \\
Adubo químico & $116^{\mathrm{ab}}$ & 0,22 & 6,75 & $4,91^{\mathrm{ab}}$ & $82,6^{\mathrm{c}}$ & $40,0^{\mathrm{c}}$ \\
Digesta ruminal 1 & $113^{\mathrm{ab}}$ & 0,23 & 6,79 & $4,68^{\mathrm{ab}}$ & $85,4 \mathrm{~b}^{\mathrm{c}}$ & $46,3^{\mathrm{ab}}$ \\
Digeata ruminal 2 & $139^{\mathrm{a}}$ & 0,25 & 7,5 & $4,02^{\mathrm{b}}$ & $87,0^{\mathrm{abc}}$ & $49,1^{\mathrm{a}}$ \\
Esterco bovino 1 & $105^{\mathrm{b}}$ & 0,25 & 7,4 & $4,19^{\mathrm{ab}}$ & $88,8^{\mathrm{ab}}$ & $40,5^{\mathrm{bc}}$ \\
Esterco bovino 2 & $107^{\mathrm{b}}$ & 0,22 & 6,8 & $5,14^{\mathrm{a}}$ & $90,5^{\mathrm{a}}$ & $39,5^{\mathrm{c}}$ \\
CV (\%) & & & & & & \\
\hline
\end{tabular}

Médias seguidas de letras diferentes nas colunas diferem entre si pelo teste de Tukey, ao nível de $10 \%$ de significância.

elevadas de nitrogênio e fósforo. No caso da adubação química, o efeito parece ter sido mais imediato, tendo considerado a sua disponibilidade. Entretanto, considerando todo o período experimental, os efeitos residuais dos adubos orgânicos podem ter assegurado um maior aporte de nutrientes para as plantas, dessa maneira, resultando em maior acúmulo de matéria seca.

Para relação lâmina foliar/colmo, não houve efeito $(\mathrm{p}>0,10)$ da adubação, o que sugere que os aumentos em produtividade podem estar mais associados com o aumento do número de perfilhos. A relação lâmina foliar/colmo apresenta relevância variada de acordo com a espécie forrageira, sendo menor em espécies de colmo tenro, de menor lignificação (Alden e Whitaker, 1970; Stobbs, 1973), o que justifica, já que são características da forrageira estudada. Esse fato também pode ter ocorrido devido ao aumento da lâmina foliar e do colmo terem sido proporcionais, em resposta aos diferentes níveis de adubação, apesar da diferença na forma do crescimento das plantas em relação aos diferentes níveis de adubação.

Para o número de perfilhos basais e aéreos, foi observado efeito $(p<0,10)$ dos tratamentos usados, sendo que o maior número de perfilhos por corte foi observado na dose 2 da digesta (tabela II). Isso se deve provavelmente à elevada quantidade de fósforo presente na digesta (2\%), já que esse nutriente compõe a molécula de ATP, fonte de energia para formação de tecido, que participa diretamente na estruturação do DNA, atuando, assim, na estruturação do tecido vegetal. Assim, a grande quantidade de fósforo encontrado na digesta pode ter estimulado o perfilhamento, resultando em aumento do número de perfilhos basais e aéreos. Essa relação também foi verificada em estudo, realizado, por Oliveira et al. (2004), que observou, aumento no número de perfilhos com o aumento das doses de fósforo em Capim-deraiz (Chloris orthonoton, Doell). Resultados semelhantes também foram observados por Fonseca et al. (1998) e Fonseca et al. (2000), onde o número de perfilhos de 
Andropogon gayanus aumentou com as doses de $\mathrm{P}$, confirmando a relevância da adubação fosfatada sobre o processo de perfilhamento das gramíneas.

Não houve diferença $(p>0,10)$ para a taxa de aparecimento de folha e número de folhas vivas por perfilho. Essas características morfogênicas são pouco influenciadas pela adubação, conforme mostra estudo realizado por Gomide (1997), onde relata que o número de folhas verdes por perfilho é razoavelmente constante, conforme o genótipo, condições de meio e manejo. A duração de vida das folhas determina o número máximo de folhas vivas sobre um colmo, o que permite determinar suas características essenciais da dinâmica de crescimento de uma comunidade de plantas após o corte.

Com relação ao filocrono, observou-se que houve efeito $(p<0,10)$ dos tratamentos analisados, principalmente no tratamento que utilizou esterco bovino (10 t/ha), o que já não era esperado, considerando-se que o filocrono é o inverso da taxa de aparecimento de folhas (tabela II). Esse fato pode ter ocorrido porque a taxa de aparecimento de folhas é um índice diário, e o filocrono se estende mais no tempo, sofrendo dessa forma as variações ambientais, já que o filocrono e o intervalo de tempo que uma folha leva para se desenvolver.

Em relação à altura das plantas no corte os tratamentos diferiram entre si $(p<0,10)$, observando-se os maiores valores médios para a maior dosagem de esterco bovino, notando-se, assim, que houve para esse tratamento um maior crescimento vertical da planta, sem comprometer, no entanto, a relação lâmina foliar/colmo neste tratamento (tabela I). Para o diâmetro da touceira, houve efeito dos tratamentos $(\mathrm{p}<0,10)$, onde o tratamento com digesta na maior dosagem resultou em maior tamanho de touceira (tabela II). Esse diâmetro deve estar diretamente relacionado com o maior número de perfilhos observado nesse tratamento.

Sendo assim, pode-se observar que os tratamentos com esterco e digesta na maior dosagem foram semelhantes com relação à produção de matéria seca da forragem de capim-buffel (tabela I). Apesar de terem apresentado características em seu desenvolvimento diferenciadas, na qual o esterco resultou em plantas mais altas. Diferentemente do que ocorreu com o tratamento que utilizou a maior dosagem de digesta ruminal, onde as plantas perfilharam mais e apresentaram maior diâmetro de touceira, resultando em produção de matéria seca semelhante.

Com relação ao efeito da época de corte, observou-se diferença $(\mathrm{p}<0,10)$, para a produção de matéria verde, produção de matéria seca e para relação lâmina foliar/ colmo. O terceiro corte apresentou maiores valores de produção e relação lâmina foliar/ colmo. O corte estimulou o perfilhamento, tendo assim, um aumento no número de perfilhos menores, aumentando a relação lâmina foliar/colmo com o passar do tempo.

Conforme Chapman e Lemaire (1993), fatores ambientais como qualidade de luz e temperatura podem afetar características como densidade de perfilhos e número de folhas por perfilho, além de características estruturais da pastagem, as quais determinam o Índice de Área Foliar (IAF) da planta. Observou-se o aumento na quantidade de perfilhos basais e aéreos com o avanço dos cortes no tempo (tabela IV). Isso pode explicar os maiores valores de produção da matéria verde produção de matéria seca, observados com o passar dos cortes (tabela III). Da mesma forma, a variável altura das plantas (tabela IV), foi influenciada $(\mathrm{p}<0,10)$ pela época de corte, tabela $\mathbf{V}$, sendo que na segunda avaliação obteve-se a maior altura das plantas.

Houve diferença $(p<0,10)$, para o perfilhamento e para taxa de aparecimento de folhas nas diferentes épocas de corte, onde no corte três observou-se o maior número de perfilhos e mais elevada taxa de aparecimento de folhas. Esse fato se deve principalmente aos efeitos climáticos da 
Tabela III. Valores médios da produção de matéria verde (PMV), produção de matéria seca (PMS) e relação lâmina foliar/colmo (L/C) em capim-buffel cv. Molopo, para os três cortes avaliados; médias de seis tratamentos de adubação. (Average values and coefficient of variation of fresh matter production (PMV), dry matter production (PMS) and leaf/stem ratio (L/C) in buffel grass cv. Molopo for three cuts evaluated. Average of six treatments of fertilization).

\begin{tabular}{lccc}
\hline Tratamentos & PMV(t/ha) & PMS(t/ha) & L/C \\
\hline Corte 1 & $6,7^{\mathrm{b}}$ & $1,3^{\mathrm{b}}$ & $0,6^{\mathrm{c}}$ \\
Corte 2 & $6,9^{\mathrm{b}}$ & $1,8^{\mathrm{a}}$ & $1,1^{\mathrm{b}}$ \\
Corte 3 & $8,0^{\mathrm{a}}$ & $1,8^{\mathrm{a}}$ & $1,3^{\mathrm{a}}$ \\
\hline
\end{tabular}

Médias seguidas de letras diferentes nas colunas diferem entre si pelo teste de Tukey, ao nível de $10 \%$ de significância.

região, observados no período de realização do experimento. Segundo estudo feito por Gomide(1997), o perfilhamento da forrageira é favorecido sob condições de alta intensidade luminosa e temperaturas não elevadas favorecem o acúmulo de fotoassimilados nas plantas.

Segundo Brougham (1960), o progressivo aumento de folhas por perfilho e de perfilhos por planta determina o aumento do IAF do relvado e, consequentemente, o rendimento forrageiro, via crescente percentual de intercepção e captura da radiação luminosa. Esse fato explica o desempenho da planta em aumentar seu IAF em resposta às variáveis climáticas. Qualquer alteração na temperatura ou qualidade da luz produz alterações no IAF, no tamanho das folhas, no número máximo de folhas por perfilho e na densidade populacional de perfilhos, como demonstrado por Lemaire e Agnusdei (2000). Assim, houve um aumento no perfilhamento e na taxa de aparecimento de folha, o que provavelmente, promoveu aumento da área de absorção de luz, já que se deduz que com
Tabela IV. Valores médios do número de perfilhos (NP), taxa de aparecimento de folhas (TApF), número de folhas vivas por perfilho (NFVP), filocrono (FILO), altura de corte (AC), diâmetro da touceira (DIAM), taxa de aparecimento de perfilho em capimbuffel cv. Molopo para os três cortes avaliados; médias de seis tratamentos de adubação. (Average values and coefficient of variation of number of tillers (NP), leaf appearence rate (TApF), number of green leaves per tiller (NFVP) phyllocron (FILO), plant height (AP) and diameter of shoots (DIAM) in buffel grass cv. Molopo. for three cuts evaluated. Average of six treatments of fertilization).

Tratamentos NP TApF NFVP FILO ${ }^{2} \mathrm{AC}^{3} \mathrm{DIAM}^{3}$

$\begin{array}{lllllll}\text { Corte } 1 & 96,5^{\mathrm{b}} & 0,18^{\mathrm{c}} & 4,8^{\mathrm{c}} & 5,7^{\mathrm{a}} & 85,3^{\mathrm{b}} & 42,1\end{array}$

$\begin{array}{lllllll}\text { Corte } 2 & 93,7^{\mathrm{b}} & 0,21^{\mathrm{b}} & 8,4^{\mathrm{a}} & 4,8^{\mathrm{b}} & 93,6^{\mathrm{a}} & 42,8\end{array}$

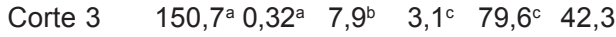

Médias seguidas de letras diferentes nas colunas diferem entre si pelo teste de Tukey, ao nível de 10\% de significância.

${ }^{1}$ folhas/dia; ${ }^{2}$ dias; ${ }^{3} \mathrm{~cm}$.

a baixa da temperatura teve decréscimo na intensidade da radiação. Esse fato é descrito em estudo feito por Casal et al. (1987), onde relatam que a produção de perfilhos por planta é também regulada pelo aumento do IAF.

Houve efeito $(\mathrm{p}<0,10)$ da época de corte para o número de folhas vivas por perfilhos. $\mathrm{O}$ número de folhas vivas (NFVP) se

Tabela $\boldsymbol{V}$. Variáveis climáticas registrada na estação metereológica do Instituto $\mathrm{Na}$ cional do Semi-Árido, durante o período experimental. (Climatic variables taken in the meteorological station of Instituto Nacional do SemiÁrido).

Fevereiro Março Abril Maio Junho

\begin{tabular}{lccccc}
\hline Precipitação & 0,7 & 407,3 & 56,9 & 83,4 & 47,5 \\
Temperatura & 27,6 & 26,3 & 24,6 & 23,9 & 22,3 \\
Nebulosidade & 7,1 & 6,9 & 7,9 & 8,2 & 7,9 \\
\hline
\end{tabular}


estabiliza quando as folhas mais velhas começam a senescer. Para o capim buffel, neste estudo, o número de folhas por perfilhos variou de 4,8 a 8,4. Segundo estudo realizado por Lemaire e Chapman (1996), o número constante de folhas verdes por perfilho, embora geneticamente determinado, varia com as condições de meio e manejo da pastagem. Dessa forma, o número de folhas do perfilho varia em função das características do ambiente e do manejo. No caso específico desse estudo, essa variação ocorreu principalmente por causa das variáveis ambientais.

Conforme observado na tabela IV , houve diferença $(p<0,10)$, para o filocrono em relação às avaliações. Isso se deve provavelmente às variações climáticas ocorridas na época do experimento. O filocrono varia conforme a espécie forrageira, mas, para um mesmo genótipo, res-

\section{BIBLIOGRAFIA}

Alden, W.G. and Whitaker, I.A. 1970. The determinants of herbage intake by grazing sheep: the inter relationship of factors influencing herbage intake and availability. Aust. J. Agr. Res., 21: 755-766.

Braile, P.M. 1971. Despejos Industriais. $1^{a}$ edição. Editora Livraria Freitas Bastos S.A. Rio de Janeiro. Brasil.

Brougham, R.W. 1960. The effects of frequent hard grazing at different times of the year on the productivity and species yields of a grassclover pastures. New Zeal. J. Agr. Res., 3: 125136.

Casal, J.J., Sanchez, R.A. and Derigibus, V.A. 1987. Tillering response of Lolium multiflorum plants to changes of red/far red ratio typical of sparse canopies. J. Exp. Bot., 38: 1432-1439.

Chapman, D.F. and Lemaire, G. 1993. Morphogenetic and structural determinants of plant regrowth after defoliation. In: International Grassland Congress, 17. Proceedings.... SIR Publishing. Palmerston North. pp. 95-104.

Durigon, R., Ceretta, C.A., Basso, C.J., Barcellos, L.A.R. e Pavinato, P.S. 2002. Produção de forragem em pastagem natural com o uso de ponde à época do ano em decorrência das condições de luz, temperatura e umidade no solo (Wilhelm e McMaster, 1995).

\section{CONCLUSÕES}

A digesta bovina promove incrementos no desenvolvimento, principalmente em relação ao perfilhamento, e na produção de matéria seca do capim-buffel. A utilização da digesta bovina como fonte de adubo, pode ser uma opção para as regiões com escassez de esterco bovino.

\section{AGRADECIMENTOS}

Ao Programa de Capacitação Institucional do Ministério de Ciência e Tecnologia pela concessão da bolsa e ao Instituto Nacional do Semi-Árido pela oportunidade de desenvolver a pesquisa.

esterco líquido de suínos. Rev. Bras. Ciencia Solo, 26: 983-992.

Espinoza, M.W., Santos Paz, A.M.A., Ribas, M.L.O., Sangoi, R.F. e Bursztejn, S. 1998. Índices para o cálculo simplificado de cargas orgânicas e inorgânicas presentes em efluentes industriais. Em: XXVII Congresso Interamericano de Engenharia Sanitária e Ambiental. AIDIS/ABES. Porto Alegre.

Fonseca, D.M., Gomide, J.A. e Alvarez, V.H. 1998. Absorção, utilização, perfilhamento e níveis críticos de fósforo em gramíneas forrageiras. Em: Reunião Anual da Sociedade Brasileira de Zootecnia, 35. Botucatu. Anais... Botucatu. pp. 312-314.

Fonseca, D.M., Gomide, J.A. e Alvarez, V.H. 2000. Absorção, utilização e níveis críticos internos de fósforo e perfilhamento em Adropogon gayanus e Panicum maximum. Rev. Bras. Zootecn., 29: 1918-1929.

Gomide, J.A. 1997. Morfogenese e análise de crescimento de gramíneas tropicais. Em: Simpósio Internacional sobre Produção Animal em Pastejo. UFV. Viçosa. Brasil. pp. 411-430. Lemaire, G. and Agnusdei, M. 2000. Leaf tissue 


\section{EDVAN ETAL.}

turn-over and efficiency of herbage utilization. In: Lemaire, G., Hodgson, J., Moraes, A., Nabinger, C. and Carvalho, P.C.F. (Eds.). Grassland ecophysiology and grazing ecology. $\mathrm{CAB}$ International. Wallingford. UK. pp. 265-288.

Lemaire, G. and Chapmand, D.F. 1996. Tissue flows in grazed plant communities. In: J. Hodgson and A.W. Illius. The ecology and management of grazing systems. CAB International. Wallingford. UK. pp. 3-36.

Menezes, R.S.C. e Sampaio, E.V.S.B. 2002. Simulação dos fluxos e balanços de fósforo em uma unidade de produção agrícola familiar no semi-árido paraibano. Em: Silveira, L.M., P. Petersen, E. Sabourin. (Org.). Agricultura familiar e agroecologia no semi-árido: avanços a partir do Agreste da Paraíba. Rio de Janeiro. pp. 249-260.

Mourales, M.M., Xavier, C.A.N., Silva, A.A. e Lucas Júnior, J. 1998. Uso da compostagem para o tratamento de resíduo sólido de abatedouro de bovinos. Em: VI Encontro Latino Americano de Pós-Graduação. Universidade do Vale do Paraíba. Anais... Jacareí. pp. 2077-2079.

Nagel, C.C., Da Costa, A.C.S. e Padre, J.G. 2008. Destinação ambientalmente correta de resíduos das indústrias de abate bovino e couro. Disponível em: http://www.pec.uem.br/ pec_uem/revistas/revista\%20APADEC/ trabalhos/c-6_laudas/NAGEL, \%20Cornelia\% 20Cristina.pdf. (10/01/2008).

Oliveira, T.N., Da Paz, L.G., Santos, M.V.F., Dubeux Júnior, J.C.B, Ferreira, R.L.C., Pires, A.J.V e Silva, M.C. 2004. Influência do fósforo e de regimes de corte na produtividade e no perfilhamento do capim-de-raiz (Chloris orthonoton Doell). Rev. Bras. Zootecn., 33: 6067.

Oliveira, M.C., Souza, F.B. e Silva, C.M.M.S. 1998. Capim buffel, preservação ex-situ e avaliaçao aprofundada. Em: Manoel Abílio de Queiroz. (Org.). I Encontro de Genétuca de Petrolina. Embrapa Semi-árido. Petrolina-PE.

Quraishi, M.A.A., Khan, K.G. and Yaqoob, M.S. 1993. Range management in Pakistan. Qazi Publications. Lahore. Pakistan.

SAS Institute. 1993. SAS/STAT. User's guide statistics. Versão 6, $4^{\text {a }}$ ed. Cary, USA.

Sabourin, E., Silveira, L.M., Tonneau, J.P. e Sidersky, P. 2000. Fertilidade e agricultura familiar no Agreste Paraibano: um estudo sobre o manejo da biomassa. CIRAD-TERA/ASPTA. Esperança-PB. 59 pp.

Santos Junior, J.D., Monteiro, F.A. e Lavres Junior, J. 2004. Análise de crescimento do CapimMarandu submetido adoses de N. Rev. Bras. Zootecn., 33: 1985-1991.

Skinner, R.H. and Nelson, C.J. 1995. Elongation of the grass leaf and its relationship to the phyllochron. Crop Sci., 35: 4-10.

Stobbs, T.H. 1973. The effect of plant structure on the intake of tropical pastures. Variation in the bite size of grazing cattle. Aus. J. Agr. Res., 24: 809-819.

Wilhelm, W.W. and McMaster, G.S. 1995. Importance of the phyllochron in studying development and growth in grasses. Crop Sci., 35: 1-3.

Archivos de zootecnia vol. 59, núm. 228, p. 508. 